\section{NOTES ON GEOMYS BURSARIUS, THE POCKET-GOPHER.}

BY HENRY LESLIE OSBORN, PH.D., ST. PAUL, MiNNESOTA.

Pending the publication of a fuller account of this interesting creature, it seems to be worth while to call the attention of students of the subject to some of the more interesting points already determined. The animal is well known in the northwestern United States, where in some regions, its habits protecting it from capture, it becomes a very great pest. In the vicinity of St. Paul, Minn., its traces are to be seen in open fields, where it can be recognized by the mounds of finely grained dirt that mark its excavating operations. It is very shy and largely nocturnal, but in more sparsely settled places it is seen in the day-time. I have never seen it in the fields that are near my home, but its mounds are common about here everywhere. The fossorial habit is thus less positive and exclusive than in the mole and in the mole-rat of Europe. Yet this animal is truly subterranean, and its structure in many interesting ways is a departure from that of ordinary rodents. In its work of digging it goes into its burrow head foremost, using the head and fore limbs nearly equally. The dirt as it is loosened is first kicked under the animal till it is collected in a mass, when the creature turns about and with the fore limbs pushes it up out of the way. The animal is thus an important agent in this vicinity in that work of the circulation of the ingredients of the soil that Darwin showed us is one of the important parts played by earth-worms in the world economy.

The Pockets.-The anterior part of the head of the pocket gopher is unusually elongate for a myomorph, so that the incisors are pushed out a long way in front of the molar region. This anterior region is, by reason of the great compression of the palatal region and the consequent narrowing of the roof of the mouth, well adapted for the ingrowth of the hairy portion of the upper lip, so that the latter surrounds the upper incisors, reducing the palatal area to a very narrow groove in the centre of the roof of this part of the mouth chamber. The entire roof of the mouth is covered with hair and is closed behind at the level of the molar teeth by a constriction that leaves only a circular opening at the rear closed by the short tongue. This anterior portion of the mouth may be called the vestibule, as it leads also to the pockets. It is really more external than internal, and this character is of importance in the use of the mouth as an organ of excavation. The pockets are apparently the homologue of the cheeks. They are bounded by a fold of skin on the outer side which arises from the maxillary region of the face and runs downward to the lower jaw some distance behind the bases of the lower incisor teeth. ${ }^{2}$ Inside this fold of skin the pockets run backward to the level of the hinder border of the scapula. The pockets thus situated are lined internally with the softest hair and like the vestibule already noted are really external cavities and not a part of the mouth. The indications from a study of the pockets in other rodents, as well as from the anatomy of Geomys, are that the pockets, though thus external, are the homologues of the cheek cavities and that the clothing of hair is a secondary character.

The muscular structure of the pockets is interesting. The muscles are presumably part of the paniculus carnosus, though they are directly attached to the bony skeleton specialized for their peculiar functions. There are three distinct sets of muscles present; these are, first, a circular muscle that runs around the margin of the pocket in its outer bounding fold. This by its contraction would seem to purse the opening of the pocket. The second set of

ISee Baird, U.S.P.R.R., vol. viii., pl, xxxi. muscles are those that I will call the protractors of the pockets. These are two in number on each side. They are spread out in the skin of both the inner and outer posterior portions of the pockets, and their fibres converge forward to finally form somewhat definite bands. The outer of these is attached in the skin at the origin of the fold on the upper jaw. The other is attached to the lower attachment of the fold at the lower jaw. These two muscles thus surround the pocket, and their contraction pulls its recess forward to the opening of the vestibule. The third set of muscles are the retractors of the pocket. These arise funnel-wise from surface of the pocket both on its inner and outer aspects, and they run backward and dorsally parallel to the fibres of the latissimus dorsi and totally free from the skin. They form a band three or four inches long and nearly an inch wide and are finally inserted in the tendinous aponeurosis that covers the in-

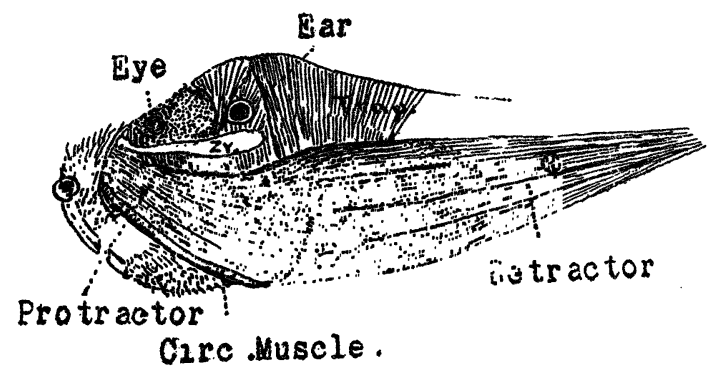

Geomys, Muscles of the pocket.
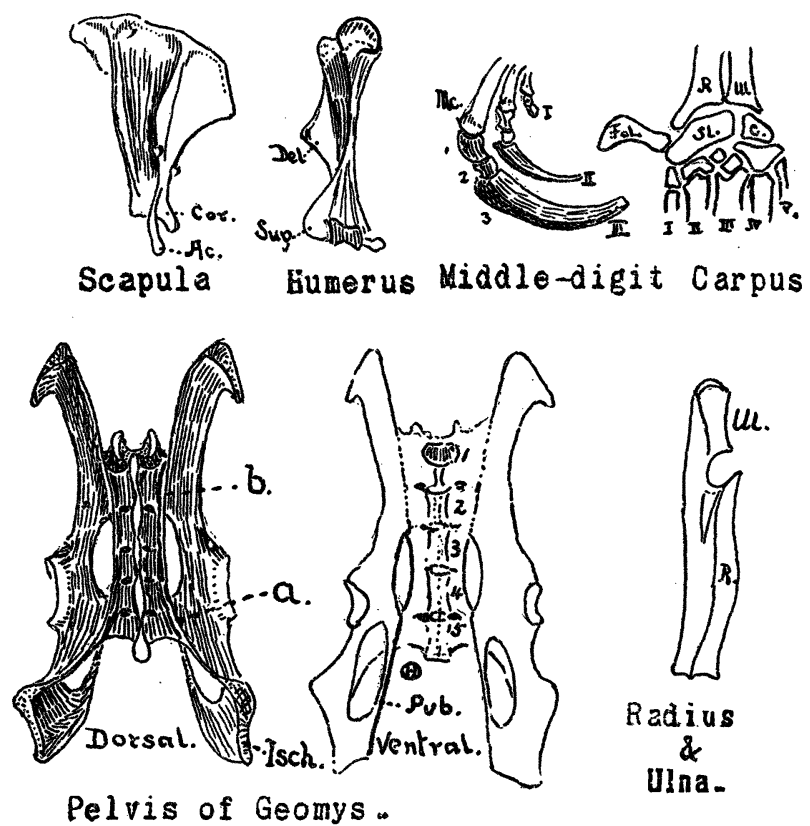

sertion of the latissimus dorsi and is attached to the neural spines of the anterior lumbar vertebræ. These by their action retract the pockets. As to the use of the pockets, it has been erroneously thought in general among the people where the gopher is common that its pockets are used in the removal of dirt. Not a single well ascertained fact can be cited in proof of this notion, and it has been certainly ascertained that the pockets are used for the reception of the harder portions of the food which are removed in them to be stored away for winter use. The softer parts of the food are eaten and digested at the time.

The Vertebral. Colum . - The cervical vertebræ, seven in number, are rather small, and in this way it results that 
the neck region is short and the head brought nearer the shoulders. This diminution of the size of these vertebra is not confined to any one, but is shared by them all. The second, however, has' a very large neural spine. 'The seventh cervical vertebra is peculiar in being closely related to the first dorsal by its transverse processes, and the tubercle of the first rib articulates nearly equally with this cervical and with the first dorsal. The first rib is unusually stout, and its head is somewhat enlarged. The vertebra of the back and loins do not call for special comment; there are twelve dorsal and seven lumbar vertebra. It is perhaps worth while to note in passing that the lumbar vertebræ do not present any of those strong processes so noticeable in many of the rodents (as for example Lepus), but they are small and compact. The sacrals are, however, very exceptional in their character. There are five vertebræ in the sacrum. 'These are immovably anchylosed by their transverse processes into one piece. Their neural spines are widened and thickened at the summits so as to form a longitudinal ridge with only small openings between the spines. In the same way the lamina of the arches are broadened and flattened to form an area sharply ridged on the margin and which posteriorly meets and anchyloses with growth from the ischium in a manner somewhat recalling the pelvis of a bird. A somewhat similar condition is to be found in the pelvi of the two-toed sloth, Chelopus hofmanii. The first and second sacral vertebræ are immovably grown to the iliac bones by a surface that extends over the entire inner side of the ilium of each side, and the third sacral vertebra joins partially in the formation of this articulation. The fourth is free laterally, as is the hinder part of the third, but these are completely grown to their neighbors, both before and behind. There are seventeen caudals. These are short and stout, and the anterior ones are supplied with strong processes for the attachment of strong muscles.

The Anterior Iimb. - A stout clavicle is present. The scapula is short and broad, its coracoid portion is drawn out into an unusually long process. 'The spine of the scapula is very high, and the acromial process is greatly elongate and drawn out beyond the level of the glenoid cavity. (Cf. Bathyergus.) An additional strong ridge traverses the posterior border of the scapula, to which the immense triceps is attached. The humerus is short and stout, its deltoid ridge is very strong and angular, the distal end is very broad and drawn out on either side into huge areas for muscular attachment. 'There is no entepicondylar foramen (though one is often present in rodents) ${ }^{2}$. The radius and ulna are short and strongly compressed and furnished with sharp angular ridges that traverse their length. 'The olecranon process of the ulna is very long and strong, as is to be expected from the huge triceps already referred to. A long curving bone, "falciform," is articulated to the radial side of the wrist in addition to the pisiform bone. 'This is the supporting piece for the great callosity of the wrist. The metacarpals are not of equal size, the first and second being smaller and the middle one being the largest. The first row of phalanges is short, and the second row is reduced almost to a merest rudiment; the distal, ungual, phalanges, however, are large, and the middle one is largest of all. This is with reference to the production of the immense nail, which is the chief one used in the

2The statement occurs in Flower and J,eddeker's " The Mammalia I iving and Fixtinct," p. 446, as well as in the article " Mammalia," in "'The Fincy. Brittanica," fromerus the former is largely a reprint, that "in all existing forms of rodents the hum there are a number of cases where the foramen is normally present. I do not know
but of any Hystricomorphs in which the foramen is present, and it is not present in the Leporida, but in many of the Suromorphs and Myomorphs it is present. 1 have (ol) served it in the following yenera: Sciuropterus, spermophilus, Cynomomrus, Haploclon and it is absent in Sciuras Tamias, Castor; it is present in the Myomorphs, Hesperomys, Onychomys, Zapus, Lipodomys, Cricetus, and absent in many closely allied forms, such as Mus, Fiber, Myodes, Cunioulus, (itomys, Gerbillus, (jeorychus,
Alactaga. act of digging. This reduction of the proximal phalanges so as to allow a more direct pull on the terminal digit, where the chief resistance comes, is paralleled in the structures of the fore limb of cetaceans, for instance. The reduction of the neck in the gopher is also a similar case.

'The Posterior Limb. - The pelvic bone has already been partly described in speaking of the sacrum. It is so peculiar that it will require a somewhat detailed description. 'The accompanying drawings will help to make the matter clearer. The iliac portion of this bone is divided on its ectal surface by a very strong ridge into two parts, above and below the ridge, respectively. This ridge, furthermore, terminates anteriorly in a hook-shaped process which projects obliquely outward and backward. The ischial portion of the pelvis is drawn out into three strong processes, the most anterior of which is, as already stated, anchylosed firmly to the sides of the fifth sacral vertebra. The pubic portion of the pelvis is reduced to a narrow and very slight bone, which, instead of running inward to meet its mate and form a pubic arch, as is general in the mammalia, runs parallel or divergingly, according to the sex of the specimen. In the female there is no symphysis pubis, the two sides being widely divergent, as in birds. In the male the pelvis is much like that of the female, but there is a narrow bridge of bone across the interval between the widely parted parallel pubic bones. The appearance of this leads one to regard it rather as an ossification in tendon than any portion of the pubic bone. I have not as yet, however, had the good fortune to see any embryonic material and have no proof to offer on the homology of this structure.

The femur is not nearly so stout as the humerus. The tibia and fibula are anchylosed, as is usual in Myomorphs. The fibula is very slender. The hinder foot is small and not peculiar, the work of digging being apparently confined wholly to the anterior limb.

\section{AN IMPJACHMENT OF "SCHOOL BOTANY."}

HY (IEORGF H. HUIOSON, VICE-PRINCIPAL STATE NORMAL ANI) TRAINING S.CHOOI, PLATTSBURGH, N. Y.

I AM in hearty sympathy with the protest in Science for Oct. 20 , 1893 , entitled "A Mistake in Teaching Botany," and for that reason cannot let the communication under the same title in Scicnce of Dec. 8 pass without criticism.

'lo avoid confusion I wish it to be distinctly understood that the following remarks are made with reference to botany in the high school and not in the kindergarten nor in the elementary schools. Bearing this in mind, let us first take the statement of the critic, on page 318 , that "There was, some years ago, a disposition to begin the study of a science at the bottom and work upward, . . . But a few years' test showed the many disadvantages of this method, and the opposite, or older, plan has been readopted." 'This statement is, to say the least, unfortunately expressed. I have yet to see an arithmetic that begins with cube root and works doncmuard to notation and numeration, and I have yet to meet a teacher of this, the oldest of our sciences, who advocates such a course because the opposite "savors of book arithmetic." I know of neither text book nor teacher who would take a high school class in United States history, begin with the Hawaiian affair and reverse the order of events until he had traced backwards the discovery voyage of Columbus and left him petitioning for vessels to enable him to reach the Fast Indian Archipelago by sailing out into the unknown west; and I know of no reason why a " natural history" of the rise, progress, and condition of animal or vegetable life should take a similar course.

An interesting lesson may be drawn from the com. 